\title{
Using the EU-SILC to model the impact of the economic crisis on inequality
}

\author{
Cathal O'Donoghue ${ }^{1 *}$, Jason Loughrey ${ }^{1}$ and Karyn Morrissey ${ }^{2}$
}

\author{
* Correspondence: \\ cathal.odonoghue@teagasc.ie \\ ${ }^{1}$ Teagasc Rural Economy and \\ Development Programme, Teagasc \\ Mellows Campus, Athenry, Ireland \\ Full list of author information is \\ available at the end of the article
}

\begin{abstract}
In this paper we attempted to chart the impact of the early part of Ireland's economic crisis from 2008-2009 on the distribution of income. In order to decompose the impact of changes in different income components, we utilised a microsimulation methodology and the EU-SILC User Database. This simulation based methodology involved the disaggregation of the 6 main benefit variables in the EU-SILC into 17 variables for our tax-benefit model. Validating, our results were positive, giving us confidence in our methodology. We utilised the framework to model changes in the level of income inequality from the period just before the crisis in 2004 to the depth of the worst year of the crisis in 2009. In terms of the impact of the economic crisis, we found that income inequality fell in the early part of the crisis modelled in this paper. Much of this change was due to rising inequality of market incomes, (even when discounting unemployment). This was due to the differential effect of the downturn on different sectors where some sectors such as the construction and public sectors were significantly hit, while the international traded sectors have been relatively immune from the downturn and have seen continued growth. The impact of the tax-benefit system has been to mitigate this upward pressure, with a gradual rise in the redistributive effect of the tax-benefit system driven by an increase in demand on the benefits side and increased progressivity on the tax side.

Jel codes: $\mathrm{H} 22, \mathrm{H} 55, \mathrm{C} 15$

Keywords: Economic crisis, Inequality, Microsimulation modelling
\end{abstract}

\section{Introduction}

Ireland's economic crisis is well documented. During a very high growth period, the GDP per capita of the country grew from below the EU15 average in 1997 to a high point of $148 \%$ in $2007 .{ }^{1}$ Ireland subsequently entered a severe economic decline in late 2007. The annual period up to quarter 42009 (the lowest quarter) witnessed a fall in GDP (in constant prices), a measure of national output, of $11.5 \%$ from its peak in quarter 42007 (the peak). The fall in GNP, a measure of national income, was even greater with a $15.6 \%$ fall from peak in quarter 42007 to its floor in quarter 1, 2011. At this point real GDP was equivalent to the value in quarter 4 2005.

Whelan (2010) discusses some of the reasons and implications of the economic crisis. Firstly as a small open economy, it was inevitable that Ireland would be significantly affected by the global economic and financial crisis. The construction related boom that characterised the last years of the boom period saw the share of the workforce working in construction reach an unsustainable $13.3 \%$ of the work

\section{Springer}

(C) 2013 O'Donoghue et al.; licensee Springer. This is an open access article distributed under the terms of the Creative Commons Attribution License (http://creativecommons.org/licenses/by/2.0), which permits unrestricted use, distribution, and reproduction in any medium, provided the original work is properly cited. 
force in 2007, fully 5 percentage points higher than most other EU countries. While the full extent of the crisis was largely unforeseen, there existed a number of conditions for a slowdown in growth numbers. For instance, by 2007 the demographic changes were no longer contributing to economic growth as the size of the labour force peaked. Productivity growth had also slowed.

The period of economic growth also witnessed changes in the composition of fiscal policy from income taxes to property capital gains taxes and VAT, which were largely related to the property boom. The ending of the property bubble saw construction employment decline from 270,000 in early 2007 to 126,000 at the end of 2009 and government tax revenues plummeted by nearly $18 \%$ from the resultant unemployment as well as the loss of tax revenues associated with construction, while public expenditure on transfers increased from $€ 18.7$ billion in 2007 to $€ 23.5$ billion in 2009 . The collapse of the property bubble left most of the Irish banks in precarious positions as a result of collateral collapsing due to the fall in property values in the region of $40 \%$, resulting in the state stepping in to guarantee the banks.

O'Riain (2012) used insights from economic sociology to further explore this financial aspect of the crisis and identifies the reduction in the capital gains tax rate from 40 to 20 per cent in 1998 as a catalyst for the rapid growth in property investment. The share of total credit going to construction and real estate rose steadily from 7\% in 2000 to $17 \%$ in 2004 and $28 \%$ in 2007, the increase in the final three years of the boom being largely due to loans to property developers, a point also made by Whelan. The share of corporate profits due to the banking sector increased from approximately $8 \%$ in 2000 to 13\% in 2007 in a similar fashion to the trend in the United Kingdom. By contrast, in France and Germany where the impact of recession was much less severe, the share of bank profits changed little during the boom although banks in both countries became much more reliant upon international lending during this time.

The economic crisis manifested itself in changes both to the labour market, wages, prices including housing costs and public policy changes to tax, transfer and public sector pay costs. Each of these changes have quite heterogeneous impacts on the population and it is difficult to understand a priori who is impacted most by these changes. It is quite important therefore from a public perspective to understand the distributional impacts of these changes.

The impact of the decline in the labour market can be felt in the household sector in a number of dimensions. Public sector wages have been reduced via a number of policy changes which Callan and Nolan (2010) found to be progressive. Callan and Nolan (2010) examined the tax increases and welfare rate reductions between 2009 and 2010, again finding these policy changes to be progressive. As the crisis progressed, combined with increases in mortgage interest rates, households with high mortgages have faced pressures in meeting payments. McCarthy and McQuinn (2010) have considered the distributional characteristics of the ratio of mortgage interest to income ratio, finding quite significant heterogeneity. Counterbalancing falls in income 2009 and 2010 saw falls in the CPI with differential changes across commodity groups. Loughrey and O'Donoghue (2012) examined the distributional impact of these price changes.

Callan et al (2010b) utilised the EU-SILC to understand changes in inequality over time around the crisis. However comparing the income distribution of one year with another using micro-data may have a confounding effect of labour market and population 
change on the one hand and policy change in the other. Voitchovsky et al., (2012) overcame many of these obstacles in examining employee wage inequality during the boom by employing the decomposition technique of Machado and Matta (2005). This allowed the authors to distinguish between the impact on dispersion of changes in wage returns versus changes in workforce composition but excluded policy changes. The overall findings from that work are that the dispersion of hourly wages fell sharply from 1994 to 2000 as the returns to education declined but subsequently increased though much less sharply to 2007.

These kinds of microsimulation analysis are a particularly useful methodology for counter-factual simulation, which can help to explain the functioning of the tax-benefit system relative to alternatives. To decompose this effect, we would like to compare the counter factual effect of differences due to tax-benefit changes alone. Microsimulation modelling is a simulation based method using micro-data that is typically used to assess the impact of policy changes. In Ireland, the SWITCH model (Callan et al., 1994) has been used for 20 years to assess the impact of policy change on inequality (Callan et al., 2001). Callan et al. (2010) utilise a special version of the EU-SILC dataset available for Ireland for 2008. Callan et al. $(2012,2011)$ have been used to assess the impact of budgetary policy relative to a base population in 2008 adjusted for population and labour market change using reweighting and updating.

In this paper we would like to understand changes in the distribution of income over the period of the EU-SILC 2004-2009, tracking the period before and after the crisis to the year with the greatest decline. In particular we would like to assess the distributional impact of individual policy changes. Given a number of challenges associated with the EU-SILC (Figari et al., 2007), we have developed a microsimulation model of the Irish tax-benefit system for each year to understand the impact of individual taxes and benefits to help decompose this impact. In particular, the paper proposes a method to overcome some of the challenges in using the harmonised EU-SILC for microsimulation modelling.

Section 2 describes the tax-benefit microsimulation methodology used in this paper. Section 3 describes the data requirements of utilising the EU-SILC for microsimulation modelling. In Section 4, we describe the methodologies utilised for the imputation of disaggregated benefits. In Section 5, we describe the welfare impact of labour market changes over the period 2005-2009. Section 6 concludes.

\section{Methodology - tax benefit microsimulation}

Methodologically, the focus in this paper is in understanding the way in which the Irish tax-benefit system has changed over time. In this section, we describe the data requirements for modelling the system.

Changes in income inequality depend not only upon changes in market income, but also changes in tax-benefit policy. The Irish tax-benefit system falls within the Anglo-liberal category of welfare states, social transfers have primarily a poverty reduction focus based around flat rate insurance benefits, or means tested benefits. ${ }^{2}$

There are no earnings related components of the benefit system. The income taxation has a schedule with two rates and has an optional joint filing system with partial transfer of bands and credits. The 2000's have seen a move away from allowances to credits payable at the standard rate. Social insurance contributions are flat rate with a floor and 
a ceiling on payments. Increases in the value of credits has seen a gradual erosion of the tax-payer base over time, with 34\% tax-payers exempt in 2005 and 40\% in 2007.

Disposable income, defined as income after direct taxation and social benefits is calculated through the use of a static tax-benefit microsimulation model, programmed in Stata. The model simulates the main direct tax and transfer instruments

- Income Taxation

- Social Insurance Contributions (Employee, Self-Employed and Employer)

- Income and Pension Levies

- Family Benefits

- Social Assistance Benefits

- Social Insurance Benefits

Using the tax-benefit model only the level of payment of social insurance benefits are modelled, with eligibility being assumed to depend upon receipt in the data, within this paper. The tax-benefit system is stylised, focusing on the main instruments, but ignoring some tax-credits and housing related benefits. As is normal in analyses of this kind, we do not consider in this analysis the impact of other tax and public expenditure changes. Over the period of this analysis, the share of indirect taxation rose, although this was as much due to a declining rate of income taxation as a result of falling incomes, as changes in tax rules. This effect is likely to be regressive (Decoster et al., 2010). In parallel there have been reductions in public expenditure that are more difficult to quantify. However Callan and Keane (2009) made an attempt to quantify the distributional impact of some public services and Callan and Nolan (2010) attempt to quantify the distributional dimension of public expenditure cuts that related to public sector pay cuts.

In Figure 1, we describe the functioning of the tax-benefit system, simulating this system in 2005 for a hypothetical family of a single earner married couple with two children. The simulations are based upon the tax-benefit microsimulation model used in this paper. The

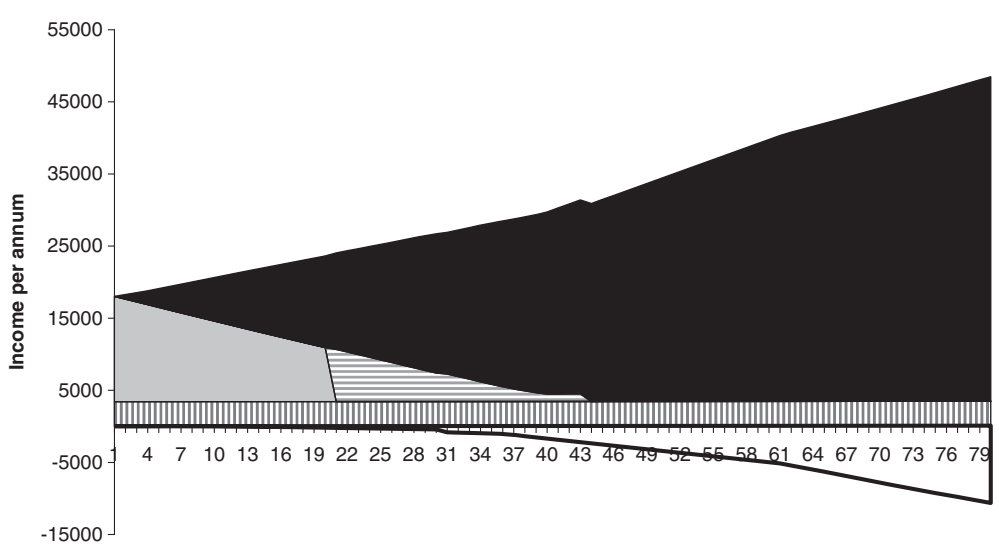

Hours Per Week

DTax, Levies \& SIC $\square$ Child Related Benefits $\square$ Social Benefits $\boxminus$ FIS $\square$ Net Market Income

Figure 1 Budget constraint diagram for 2005 tax-benefit system (with detailed decomposition of disposable income). Note: We assume here a single earner married couple with 2 children, aged $X$ and $Y$, with no direct housing costs for simplification. The main earner has a wage rate of two thirds the average wage. 
main earner is assumed to have a wage rate of two thirds of the average wage rate per hour, with hours varying from 0 hours (and seeking work) through to 80 hours per week.

In this figure, we describe the different components of disposable income, which is equivalent to the top of the graphic. Disposable income is comprised of net market income, equal to gross market income minus income taxation, social insurance contributions and income levies. Unemployment assistance is paid at zero hours and gradually tapered away with a $60 \%$ withdrawal rate up until 20 hours per week is worked. Once this 20 hour limit is reached a family income supplement (FIS), an in-work cash benefit for low income families, is paid. Child related benefits, including child benefits and from 2006 a child care subsidy for young children are also included.

In Figure 2, we report trends in the overall budget constraint over the period of respectively 2003-2007, the period up to the crash and for 2007 to 2012, the period after the crash. These budget constraints reflect the disposable income associated
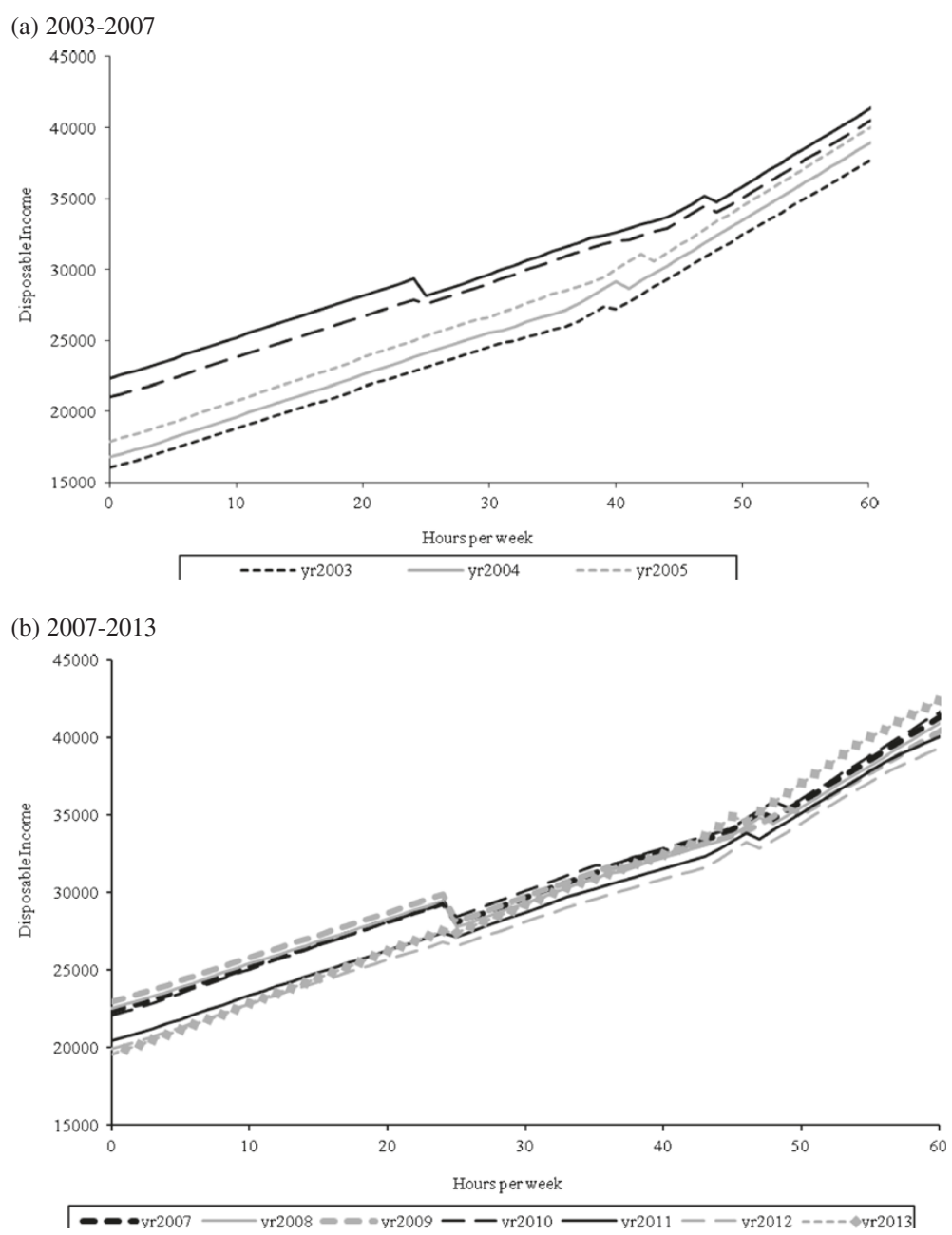

Figure 2 Budget Constraint Diagram for tax-benefit systems. Note: 1. We assume here a single earner married couple with 2 children, aged $X$ and $Y$, with no direct housing costs for simplification. The main earner has a wage rate of two thirds the average wage. 2. The budget constraints have deflated by CPI to reflect purchasing power. Wages have been assumed to grow in line with average wage growth. 3. The ages of children used in the hypotethical family are 1 and 6 . yyABCD - reflects the budget constraint for year $\mathrm{ABCD}$ ( $\mathbf{a}$ and $\mathbf{b})$. 
with different hours worked at the averages, deflating by the CPI to account for changes to purchasing power. Wages are assumed to grow at the average rate for industrial employees.

The main changes to the structure of the tax-benefit system have been outlined in Appendix 1. Most changes have been parametric, with some structural changes to "income levies" or additional taxes, social insurance contributions the introduction and abolition of a childcare supplement. Some of the changes applied to part years. In order to incorporate this, looking at annual incomes, we apply a proportion of each set of policy parameters to the appropriate number of months.

In the period to 2007, we notice that the overall budget constraint flattens, with the ratio of disposable income for 40 hours to 0 hours decreasing from 1.70 in 2003 to 1.45 in 2007. It also continues to fall to 1.39 in 2009, before rising again. The period to 2007 sees a steady rise in the level of the budget constraint as the purchasing power for all parts of the budget constraint rose as wage and benefit growth outstripped inflation. In 2008, the budget declined slightly at the top. In 2009, the purchasing power of the bottom of the distribution rose slightly, but fell at the top, with the reverse occurring in 2010. In 2011, purchasing power fell for most groups, with the bottom falling slightly more. Purchasing power continued to fall across all income levels in 2012. However in 2013 the system becomes more regressive, with purchasing power rising at the top. This rests upon our assumption that earnings will grow at the same rate as the previous year, the same assumption that is made for the CPI.

In Figure 3, we consider some of the components that drive these changes, reporting changes in the values of sectoral wage rates, CPI, tax credits and benefit levels. It is by necessity only a snap shot of a number of the changing parameters. To consider the impact of changes against purchasing power, we focus first on CPI, which rose to 2008, but then Ireland experienced deflation to 2010, before prices rose again to 2012. Working age unemployment benefits have risen the most relative to CPI, even with a nominal cut in 2009 and 2010. ${ }^{3}$ Old age benefits incurred no nominal cut, by the

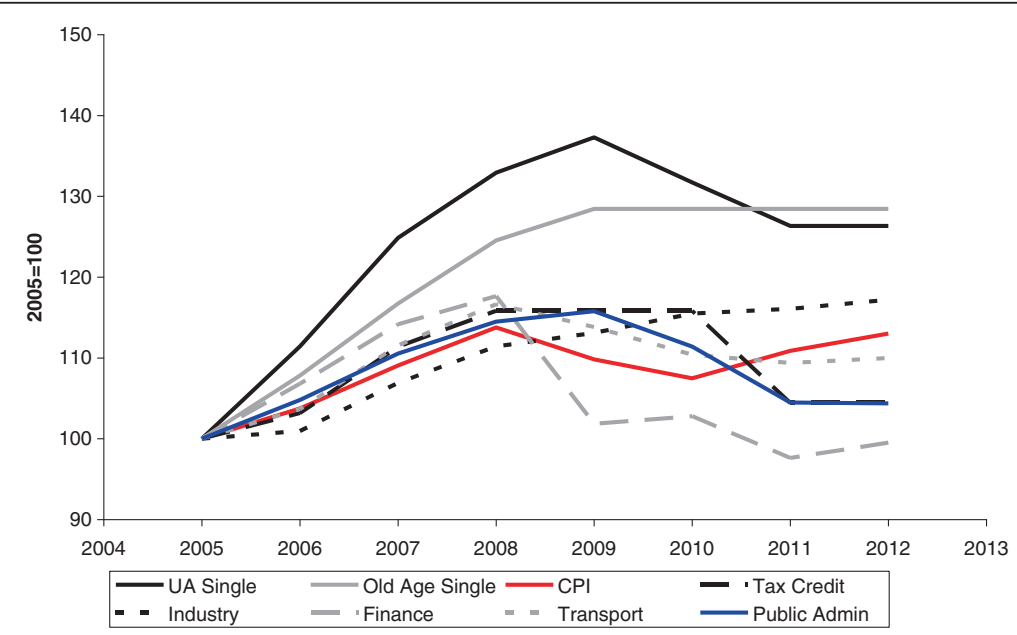

Figure 3 Growth Rate of Components of the Tax-Benefit System relative to Prices and Incomes.

Note: UA - Unemployment Benefit rate. UA Single - Unemployment Assistance for Single Person. Old Age Single - Contributory State Old Age Pension for Single Person. CPI - Consumer Price Index. Industry Average Industry Sector Wage. Finance - Average Finance Sector Wage. Transport - Average Industry Sector Wage. Public Admin - Average Public Administration Sector Wage. 
end of the period but purchasing power increased for this group. Tax credits initially rose at a rate close to CPI, but then nominal cuts relative to rising CPI saw the index dip below CPI and thus leading to fiscal drag. Of the 4 sectors considered, the financial sector, given the banking collapse has seen the largest fall relative to CPI, with the industrial, largely export based sector having wage growth exceeding CPI.

\section{Data requirements}

In order to simulate taxes or benefits, we require data with the following characteristics

- A dataset representative of the household population with appropriate weights, with sufficient sample size for sub-groups to undertake disaggregated analysis

- Data that has incomes before the application of incomes (gross incomes)

- The period of analysis may vary from instrument to instrument too, with income taxes typically assessed over a year (which may or may not align with the calendar year), while some benefits may have a period of analysis of a month. Sometimes the period of analysis for payment of a benefit (current month), may differ from the period of analysis of the means for assessment (e.g. previous year). However very few datasets allow for such heterogeneity.

\section{Data}

Understanding the impact of changes in labour market, incomes and policy measures required data with sufficient detail. SILC is a dataset that has been collected in Ireland since 2003 and is the successor to the earlier European Community Household Panel Survey. The SILC dataset collects information on incomes, labour market characteristics, demographics and living conditions and is used to undertake analyses on poverty, inequality and deprivation. We utilise data for 2004 to 2009. While data was released by Eurostat for 2010, errors were found in the data and by the time of going to print revised data had not been made available. ${ }^{4}$

The EU-SILC is collected at the national level, with harmonised version supplied to Eurostat, which is then processed and provided to researchers as a harmonised User Database (UDB). We utilise the Irish component of the EU-SILC (UDB) in which to model the income distribution. Data are provided gross of taxes and contributions. The Irish component uses partially survey and partially register data. $80 \%$ of respondents allowed their national social security number to be used to access administrative data in relation to their benefit entitlement (Callan et al., 2010).

A national weighting methodology is utilised incorporating constraints based upon (sex, age-group, region, household composition) based upon a combination of population projections based on the Census and from the Quarterly National Household Survey (Callan et al., 2010). It should be noted however that although the weights are representative of the population structure, they are not fully representative of either the social transfer recipients, of the taxable income distribution, nor of the representativity of the top of the distribution. Callan et al., (2010) proposed a reweighting methodology based upon external data to improve the representativity in this dimensions. In a survey of microsimulation models across the world, O'Donoghue and Loughrey (2013) found that about $50 \%$ of models reweighted their data to account for issues such as this. In 
this case, reweighting would result in an altered distribution of income. While this may well indeed improve the accuracy of the 'true' distribution of income in a country, it would differ from official definitions utilising the statistical office supplied weights. As a result and because the purpose of this paper is to understand the difference using the EU-SILC definition of income and associated weights, we do not make this adjustment here.

There are however a number of challenges to utilising the EU-SILC for microsimulation modelling.

Given the availability of parental and partner ID variables, it is possible to generate most (within household) units of analysis required by a tax-benefit system. However the data is not sufficient, where instruments require knowledge about inter-household units of analysis, say for higher education grants.

A challenge in the use of the EU-SILC rests in the difference between the period of analysis for the income variables, which typically are the previous year and the personal characteristics which typically relate to the time of interview. Thus one may observe people made unemployed in the interview year but with employment income in the data. Thus there may be inconsistencies between both. Ireland has a slightly different definition as the reference period spans two tax years as the "income reference period" is "12 month prior the date of interview", the end of income reference period is the date of the interview. Approximately $25 \%$ of the sample is collected in each quarter.

As both tax-benefit models and the EU-SILC, aim to measure household disposable, income, by and large, the EU-SILC has the appropriate variables required for tax-benefit modelling. However there are a number of issues. Firstly there are some missing variables such as capital gains and wealth or property values. However this is typical of most income surveys and so most tax-benefit microsimulation models make look at a definition of disposable income that does not incorporate taxes based upon these measures. It would be reasonable therefore for an EU-SILC based model to make a similar assumption.

A particular challenge to microsimulation modelling is that some of the variables are not easily attributable to the appropriate unit of analysis. For example some of the income variables that are received by individual such as capital income, rental income, private transfers, young person's income, are only recorded at the household level. Thus in practice these variables will be assigned to the head of household, which in a progressive tax system, may over-estimate the amount of taxation if some of these incomes were incident on others in the household. This is also the case with family benefits which may be incident at the nuclear family level but are only recorded at the household level. Where these instruments are taxable, this too may bias the results.

One of the most serious challenges to using the EU-SILC for microsimulation modelling is the aggregation of benefits. Within the EU-SILC, social benefits are aggregated into 6 benefits recorded at the individual level (unemployment, old-age, survivor, sickness, disability and education) plus 3 recorded at the household level (family, social exclusion, housing benefits). If it were possible, utilising other data to model all benefits, then this aggregation would not be an issue, as we could replace the data recorded benefits with the simulated benefits. However, while in practice we model most benefits in Ireland as there are no earnings related benefits, we model the value for most benefits. The Irish social science data archive makes available a variant of the SILC for Ireland 
with disaggregated benefits. However this dataset is not suitable for tax-benefit microsimulation modelling as incomes are aggregated to the household level and some variables such as age have been banded.

As we do not know the contributory conditions used for social insurance benefits, we would like to utilise benefit receipt to model the level of these benefits. For most social assistance and family benefits, we have sufficient information to model the benefit. Callan et al., (2010) have access to a special research version of the 2008 EU-SILC which does not suffer from these aggregation issues.

It should be noted however that even where we can fully model an instrument, because of benefit take-up issues, we would still like to know the value and presence of the benefit so that take-up can be modelled; although many models assume $100 \%$ take-up.

A similar issue to benefit take-up is the use of survey data to make inferences about mis-calculation of taxes and social insurance contributions. Ideally therefore taxes and social contributions would be available separately at the most appropriate unit of analysis. However within the EU-SILC, they are reported at an aggregated level in terms of the instruments being reported in a single variable and at an aggregate level in terms of being reported at the household level. However this is not a major issue as many income datasets do not have separate income tax and social insurance contribution data.

In general the EU-SILC has a relatively good availability of appropriate expenditures used in the tax and benefit system, particularly containing mortgage interest, private pension contributions and other housing costs. However in common with other income surveys, there is missing information on other deductible expenditures including medical insurance etc. The survey also does not contain the value of the residential property, which from 2013 is required in Ireland to model a local property tax.

\section{Statistical model: benefit disaggregation and property value estimation}

As identified in the last section, there are a number of barriers to utilising the EU-SILC for microsimulation purposes. A challenge in this paper is to impute disaggregated benefit entitlement. Figari et al. (2007) describe a methodology developed by Levy and Mercader (2003) for disaggregating benefits in the Spanish EU-SILC. They required splitting:

- Unemployment benefits into 2 disaggregated benefits

- Old Age Benefits into 3 disaggregated benefits

- Survivor's Benefits into 2 disaggregated benefits

Unemployment benefits in Spain can be split relatively easily as insurance benefits cannot fall below $75 \%$ of the minimum wage and assistance benefits are equal to $75 \%$ of the minimum wage (although income tested, they are not means tested). Old age benefits, except for an old age supplement that is income contingent, are relatively straightforward to disentangle as they do not overlap in terms of value. Survivor's Benefits are imputed in a similar way. Child Benefits can more or less be modelled on the basis of information in the data.

However the Irish case is (as is likely the case in many northern European countries) more complicated. This is due to the fact that there are more instruments (See Appendix 1) with more complicated rules and with overlapping values between instruments. 


\section{Methodology}

In order to impute the value of these benefits at a disaggregated level, we need to understand the characteristics associated with the receipt of each benefit and then to simulate, given the receipt of an aggregated benefit group, the value of a benefit at each level.

Conditional on receipt of an aggregate benefit in the data, we utilise the following equations to simulate the disaggregated benefits. The first objective therefore is to estimate a series of statistical models relating entitlement to a disaggregated benefit as a function of the aggregate benefit. To disaggregate these variables into their benefit components, we utilise the fact that an earlier survey, the Living in Ireland Survey (LII) 1994-2001 contains disaggregated benefits. We estimate equations of benefit entitlement in the LII and use these estimates to simulate entitlement to disaggregated benefits in the SILC data. It is in effect a parametric statistical matching method. We based this relationship on demographic characteristics, existence of other incomes, labour market characteristics of the recipient and spouse.

Depending upon whether the dependent variable is binary as in the case of survivor's benefits or old age benefits or have more than 2 categories as in the case of unemployment or disability benefits, we utilise respectively a multinomial logit model.

We choose as explanatory variables, characteristics that may be associated with the type of dependent variable. So for example for unemployment benefits, we would expect those over 55 to be more likely to claim the pre-retirement allowance. Those with higher household current market income will more likely to be in receipt of social insurance benefits. For similar reasons, those with in-work employment status will be more likely to be in receipt of social insurance. The self-employed are typically not eligible for social insurance benefits. As benefits give additional payments for dependents, and thus the taper for a means tested benefit will extend longer for a larger family, making this makes larger families more likely to be in receipt of a means tested benefit. By its nature, those in receipt of a back to work allowance are more likely to be in-work than for the other benefits. Table 1 confirms these results for unemployment benefits. The pseudo R2 indicates a reasonably good fit.

For survivor's benefits, the distinction is between means-tested and insurance benefits. In Table 2, we see as in the case of unemployment benefits that those in receipt of other incomes are less likely to be in receipt of means tested benefits. However older people are more likely to be in receipt. The fit of the model is not very good and this gets progressively worse over time, as by 2009 , only about $2 \%$ of recipients receive means tested survivor's benefits. There is a similar relationship for old age benefits (Table 3). As only the Old Age (Transitory) Pension, modelled as part of the insurance pension here, requires one to retire from the labour market, we notice that receipt of the insurance pension is highly significantly related to being retired. As in the case of survivor's benefits (Table 2), share in receipt of means tested benefits has fallen over time.

Again for disability benefit (Table 4) we observe the same pattern in relation to means tested benefits with higher other income sources reducing the likelihood of receipt. Unsurprisingly, chronic illness is relatively more important. Carer's meanwhile are more likely to be younger and have more children.

The regressions are then utilised to simulate benefits in the SILC, using proportions with aggregated category consistent with Social Welfare Statistics. The share of individuals 
Table 1 Benefit disaggregation equations (unemployment benefits) - multinomial logit

\begin{tabular}{llll}
\hline $\begin{array}{l}\text { Dependent variable } \\
\text { category }\end{array}$ & $\begin{array}{l}\text { Unemployment means-tested } \\
\text { assistance receipt }\end{array}$ & $\begin{array}{l}\text { Back-to work } \\
\text { allowance receipt }\end{array}$ & $\begin{array}{l}\text { Pre-retirement } \\
\text { allowance receipt }\end{array}$ \\
\hline Male & $0.898^{* * *}$ & 0.088 & -0.904 \\
Aged 55+ & -0.447 & -0.875 & 3.816 \\
Lose job in last year & -0.177 & -0.339 & 0.336 \\
Value of social welfare benefits & $0.835^{* *}$ & $2.355^{* * *}$ & 0.89 \\
Employment earnings & $-2.432^{* * *}$ & -0.918 & $-22.142^{* *}$ \\
Employee & 0.37 & $5.851^{* * *}$ & -36.643 \\
Farmer & $1.717^{* *}$ & 0.988 & 0.398 \\
Self-employed & $2.586^{*}$ & $8.598^{* * *}$ & -42.89 \\
Unemployed & 0.355 & -36.824 & -1.375 \\
Spouse in-work & 0.23 & $-1.263^{*}$ & 0.497 \\
Inactive & 0.135 & -36.009 & 0.888 \\
Retired & -44.891 & -40.393 & $7.074^{* * *}$ \\
Age & 0.042 & 0.088 & -0.213 \\
Age squared & -0.001 & -0.001 & 0.003 \\
Married & -0.274 & -0.25 & 0.842 \\
Widowed & 37.636 & 38.453 & -1.628 \\
Separated or divorced & -0.455 & 1.105 & 1.524 \\
Number of children aged $0-11$ & 0.074 & $0.646^{* *}$ & -2.045 \\
Number of children aged $12-15$ & 0.238 & $1.017^{* *}$ & 0.992 \\
Constant & $-1.146^{*}$ & $-8.792^{* * *}$ & -0.751 \\
Pseudo R squared & 0.5023 & & \\
\hline Note: The basecase her is & &
\end{tabular}

Note: The base case here is not in receipt of benefits.

* Significant at $10 \%$.

** Significant at $5 \%$.

*** Significant at $1 \%$

Table 2 Benefit disaggregation equations (survivor's benefits)

\begin{tabular}{ll}
\hline Dependent variable: & Survivors assistance pension receipt \\
\hline Male & -0.42 \\
Value of other benefits & $0.143^{* *}$ \\
Value of social welfare benefits & $-4.073^{* *}$ \\
Other household income & $-0.957^{* *}$ \\
Employment earnings & $-3.719^{* *}$ \\
Employee & $1.114^{* *}$ \\
Retired & -0.056 \\
Age & $0.054^{* *}$ \\
Age squared & $-0.001 * *$ \\
Number of children aged 0-11 & -0.007 \\
Number of children aged 12-15 & 0.246 \\
Constant & $1.742 * *$ \\
Pseudo R squared & 0.108 \\
\hline * Significant at 10\%. & \\
** Significant at 5\%. & \\
*** Significant at $1 \%$. &
\end{tabular}


Table 3 Benefit disaggregation equations (old age benefits)

\begin{tabular}{ll}
\hline Dependent variable: & Old age insurance pension receipt \\
\hline Male & $-0.496^{* * *}$ \\
Value of other benefits & $0.21^{* * *}$ \\
Value of social welfare benefits & $-0.971^{* * *}$ \\
Household income & $-0.422^{* * *}$ \\
Employee & -1.145 \\
Retired & $-1.157^{* * *}$ \\
Age & $0.476^{*}$ \\
Age squared & $-0.003^{*}$ \\
Married & -0.313 \\
Widowed & $-0.525^{* *}$ \\
Separated or divorced & 0.042 \\
Number of children aged 0-11 & 0.097 \\
Number of children aged 12-15 & 0.287 \\
Constant & $-18.745^{* *}$ \\
Pseudo R squared & 0.1678 \\
\hline
\end{tabular}

* Significant at $10 \%$.

** Significant at $5 \%$.

*** Significant at $1 \%$.

simulated as being in receipt of a disaggregated benefit is based on the official proportion of recipients for an aggregated benefit that are in receipt of a particular disaggregated benefit. These proportions are provided below in Figures $4 \mathrm{a}-4 \mathrm{~d}$. Individuals are imputed as being in receipt of a disaggregated benefit where the estimated probability of receipt exceeds the threshold specified by the calibration totals.

We note that as the Irish social insurance system matures and as economic change occurs, the balance between different benefits changes, for example, one can see from Figure $4 \mathrm{~b}$ that the share of survivor's insurance benefits approaches $100 \%$ while the share of survivor's assistance benefits approaches $100 \%$. In terms of the disability benefits, Figure $4 \mathrm{~d}$ shows that the share applying to invalidity insurance increases around 2006 but subsequently declines as the share for carers benefit recipients increases. As the economic crisis arose in 2008, the share of those in receipt of short term unemployment benefits rose, before falling as the share of longer termed unemployed rose as shown in Figure 4a. We utilise the equations to predict the disaggregation of highest probability and then rank this variable to select the most likely disaggregated benefits.

This imputation was evaluated against the actual data and was found not to be completely precise as a small number of individuals were predicted by these equations to receive means tested benefits, but had means too high to be eligible.

In order to evaluate this we had to run the tax-benefit system. However as noted above the Irish component of the EU-SILC has incomes that span two tax years. In order to get a more accurate measure we ran the tax-benefit system for the data interview year and for the preceding year, taking a weighted average depending upon the quarter of interview.

In order to correct these problems; individuals who were simulated to receive assistance benefits but not eligible under the precise rules were given eligibility for contributory benefits and a corresponding number of those with insurance benefits were given 
Table 4 Benefit disaggregation equations (disability benefits) - multinomial Logit

\begin{tabular}{lll}
\hline Dependent variables & $\begin{array}{l}\text { Long-term disability } \\
\text { assistance benefit receipt }\end{array}$ & Carers allowance/benefit receipt \\
\hline Male & -0.524 & -0.688 \\
Lose job in last year & -0.055 & $0.192^{*}$ \\
Value of social welfare benefits & $-0.953^{* *}$ & $-1.21^{* *}$ \\
Household income & 0.255 & 0.389 \\
Employment earnings & $-2.986^{*}$ & 0.422 \\
Employee & -0.055 & -0.437 \\
Chronic illness & $1.307^{* * *}$ & -37.911 \\
Retired & $-2.016^{*}$ & -35.843 \\
Age & 0.019 & $-0.139^{* *}$ \\
Age squared & 0 & $0.002^{*}$ \\
Married & $-2.331^{* * *}$ & 0.041 \\
Widowed & 36.067 & -1.251 \\
Separated or divorced & $-2.906^{* *}$ & 0.937 \\
Number of children aged 0-11 & 0.022 & $0.926^{* * *}$ \\
Number of children aged 12-15 & 0.077 & -0.23 \\
Constant & 1.373 & 1.624 \\
Pseudo R squared & 0.3661 & \\
\hline Note: The base case is not in reipt & &
\end{tabular}

Note: The base case is not in receipt of benefits.

* significant at $10 \%$.

** significant at $5 \%$.

*** significant at $1 \%$

eligibility for assistance benefits. A second iteration of the tax-benefit system was then used to calculate the value.

Adjustments were also made for some measurement error. For example some individuals of pension age were classified as being in receipt of working age benefits. In this case we assume a classification error and transform them to old age benefits. Where working age people are in receipt of state pensions, we transfer these to occupational pensions.

There are some period effect issues also where multiple income replacement benefit receipt occurs during a single year. As the data does not contain information on the number of months of receipt of different benefits, only the total, we make the assumption that the dominant benefit (i.e. the one with the higher value) is received for 12 months. The latter assumption is likely to bias upwards benefit receipt as it will overstate the benefits of those in receipt for less than 12 months.

A further adjustment is also made as the SILC data contains some private sector social protection instruments such as redundancy payments and some private pensions. Amounts over and above state social protection instruments, calculated using the tax-benefit model, are transferred into market income variables.

\section{Validation}

Before going further, we undertake a validation of simulation of taxes and benefits. We firstly in Table 5 consider the non take-up rate at the aggregate level. We measure take-up by comparing the proportion of simulated benefit receipt with actual benefit 


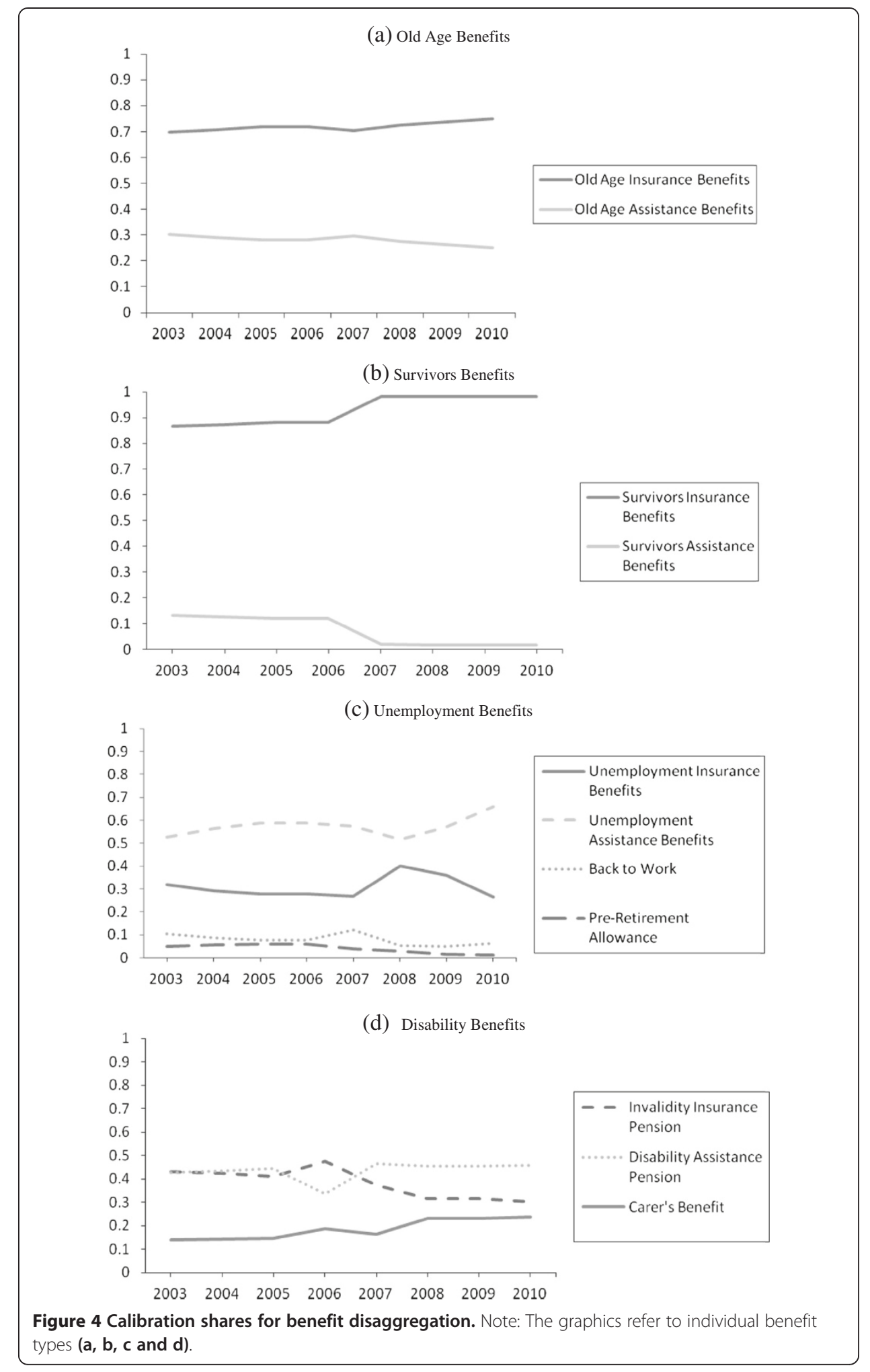

receipt in the data. As the benefit disaggregation is modelled, we compare take-up only at the level of aggregation in the raw data. Combining all benefits the non-take up rate is about 5-6 per cent, rising slightly over time. The non-take-up rate is highest amongst those in receipt of survivor's benefits and lowest amongst the elderly. To some 
Table 5 Non take-up rates by instrument

\begin{tabular}{lllllll}
\hline Take-Up & $\mathbf{2 0 0 4}$ & $\mathbf{2 0 0 5}$ & $\mathbf{2 0 0 6}$ & $\mathbf{2 0 0 7}$ & $\mathbf{2 0 0 8}$ & $\mathbf{2 0 0 9}$ \\
\hline Old Age & 2.8 & 2.1 & 1.7 & 1.9 & 2.8 & 2.7 \\
Unemployment & 8.0 & 9.8 & 9.5 & 8.6 & 7.8 & 9.1 \\
Survivor & 19.0 & 18.8 & 19.0 & 21.4 & 11.2 & 9.6 \\
Disability & 6.1 & 6.7 & 9.1 & 8.9 & 7.1 & 9.5 \\
All & 5.2 & 5.1 & 5.3 & 5.3 & 5.1 & 6.1 \\
\hline
\end{tabular}

Note: Non take up is modelled at the aggregate benefit level, at the individual unit of analysis.

extent non-take-up is underestimated in the data as much of the entitlement is generated by construction.

The next point of concern arises from the annual period of analysis. Without any data on the number of months of benefit receipt, we make the assumption of 12 months of receipt. In some cases, the amount recorded in the microdata for a particular aggregated benefit exceeds the maximum amount that can be gained from the instrument. In those cases, we reallocate the excess amount to other income. This can be the case where, for example, retirement income or lump sum pensions are recorded as part of old age benefits. Thus our methodology will tend to over-estimate insurance benefits for those with alternative income sources. In order to assess the effect of this, we utilised the equations to predict the likely receipt of disaggregated benefits, then simulated the value of each benefit and then re-aggregated them again to be able to compare with the equivalent characteristics in the data.

One source of variation from 12 months is the presence of other sources of income, particularly for income replacement benefits. In comparing average actual and simulated benefit data, and in order to avoid this confounding issue, we make our comparison by excluding those with other sources of labour market income. Figure 5 reports the ratio of simulated to actual benefit values for this sub-group over time. We note that for old age and survivor benefits, which are long-term and largely continuous, the average ratio of simulated to actual is close to one. For more transient instruments

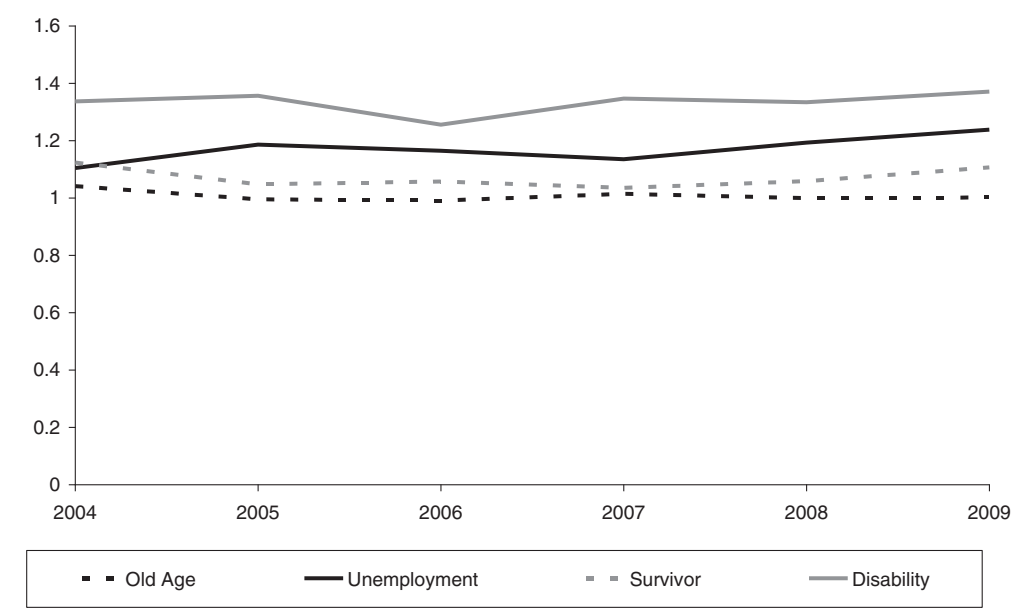

Figure 5 Ratio of average benefit of simulated to actual benefit. Note: For the purpose of this figure, we assume full-take up in the simulation and consider households with no alternative income sources. 
Table 6 Mean equivalised household incomes (actual and simulated)

\begin{tabular}{lllllll}
\hline Market income & $\mathbf{2 0 0 4}$ & $\mathbf{2 0 0 5}$ & $\mathbf{2 0 0 6}$ & $\mathbf{2 0 0 7}$ & $\mathbf{2 0 0 8}$ & $\mathbf{2 0 0 9}$ \\
\hline Simulated & 20972 & 21781 & 22992 & 24884 & 23496 & 21962 \\
Data & 20862 & 21670 & 22892 & 24740 & 23360 & 21804 \\
Ratio & 0.99 & 0.99 & 1.00 & 0.99 & 0.99 & 0.99 \\
Gross income & 2004 & 2005 & 2006 & 2007 & 2008 & 2009 \\
Simulated & 25738 & 26933 & 28659 & 31177 & 30402 & 29115 \\
Data & 24720 & 25916 & 27595 & 29975 & 28995 & 27613 \\
Ratio & 0.96 & 0.96 & 0.96 & 0.96 & 0.95 & 0.95 \\
Disposable income & 2004 & 2005 & 2006 & 2007 & 2008 & 2009 \\
Simulated & 21059 & 21927 & 23235 & 25170 & 24666 & 23182 \\
Data & 21007 & 21601 & 22970 & 25091 & 24401 & 22994 \\
Ratio & 0.99 & 0.99 & 0.99 & 1.00 & 0.99 & 0.99 \\
\hline
\end{tabular}

Notes:

1. Equivalence scale used is the modified OECD scale.

2. For validation purposes, we have not used weights in this table.

related to spells in unemployment or illness, the ratio is much higher indicating the existence of spells.

\section{Results: distributional impact of downturn}

In this section we report the results of our analysis based upon our model. We firstly track mean incomes via components market income, gross income (market plus benefits) and disposable income (gross minus taxes and contributions). We have deflated by CPI to report the change in purchasing power. In Table 6, we see that each measure exhibits the same trend, rising to 2007 and then falling to 2009 . We note that average market income is similar in real terms in 2009 to 2005. However both mean gross income and disposable income are at levels equivalent to 2006. We note for each measure, the high ratio of actual data to simulated data. Gross income is slightly lower reflecting issues associated with take-up and issues

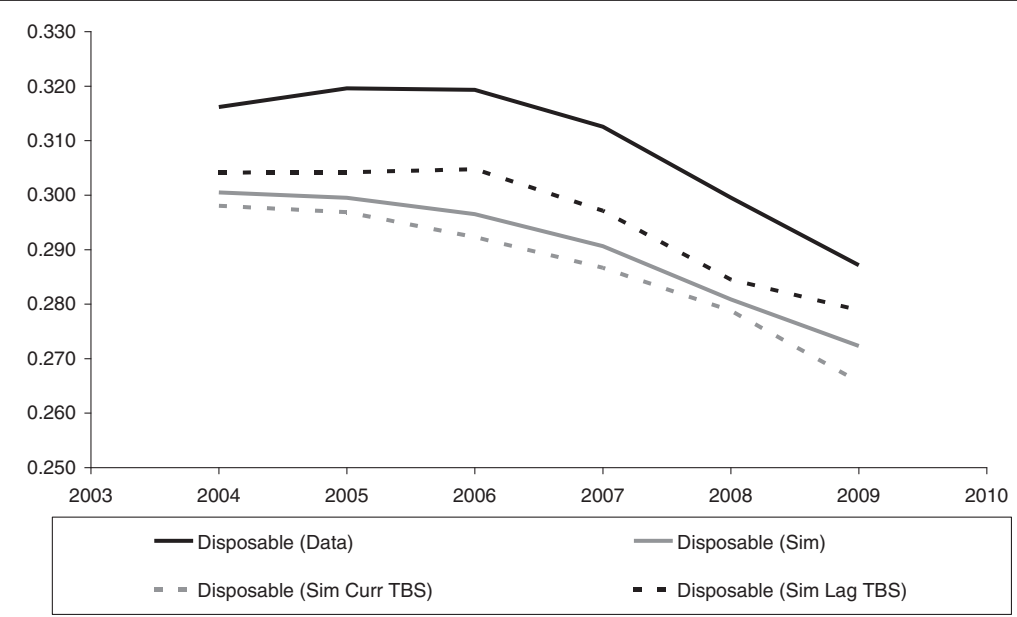

Figure 6 Distribution of disposable income, simulated and actual. Note: Equivalence scale used is the modified OECD scale. 
associated with the length of benefit receipt in a year. The ratio remains relatively constant over time.

\section{Inequality}

In Figure 4, we report the trend in the inequality of equivalised household disposable income over time. We note that inequality fell from 2004 to 2009. Thus the initial impact of the crisis in 2008 and 2009 was inequality reducing.

We validate the microsimulation model by comparing actual and simulated Gini's (Figure 6). The data year's in the Irish EU-SILC, span 2 years as incomes apply to the 12 months before the interview date, with interviews conducted more or less equally across the year. As a result we model the simulated year as the weighted average of the current and lagged year as a function of the quarter of data collection. We also report the simulation of tax-benefit systems in the current and lagged year. We note firstly due to reasons such as benefit non-take up and specification issues in the simulation of taxation such as the inability to model specific allowances, as well as tax evasion and avoidance, that there is a gap between the level of the Gini for simulated and actual equivalised disposable income. This is not surprising and consistent with other microsimulation analyses. For the period to 2009, there is not much difference in the trend between the different assumptions, with a correlation of about 0.98. Meanwhile the lagged system has a different trends (rising, but at a lower rate), with a correlation of 0.68 , resulting in the weighted average also growing at a relatively lower rate between the two measures, with a correlation of 0.88 . We would therefore conclude that the current tax-benefit system is a better predictor of trend than the lagged or weighted average.

We now try to understand the differences in the levels between the actual and simulated data as a result of the assumptions made. We focus first on the assumptions made in relation to the benefits system. We consider three alternatives, modelling

- Non take-up with the weighted average of current and lagged systems

- Non take-up and an estimate of months of benefit receipt with the weighted average of current and lagged systems

- Non take-up and an estimate of months of benefit receipt with the current system

We model take-up at the level of the benefit unit level. Take-up regressions are reported in Appendix 3. The coefficients follow the usual signs, with the higher the potential benefit receipt, the higher the take-up. Higher other sources of household income results in lower take-up. Similarly, being in employment increases take-up, while farmers have a lower take-up than other groups. Separated or divorced are less likely to take-up benefits than other groups. Interestingly, prior to the boom, those with higher education had a lower propensity to takeup social benefits, while after the crash, this effect become non-significant.

Modelling benefit non-take-up at the family level, we see that the inequality trend over time remains the same, with curve shifting about a quarter to a half of the gap closed. As noted above, part of the reason for the over-simulation of 
benefits, is that it is not possible to identify in the EU-SILC data, receipt of benefits of less than a year. Imputing the number of months received on the basis of the difference between actual and simulated benefits, we see that much of the remaining gap is closed in Figure 7. In 2009, this over-compensates pushing inequality over $100 \%$. However this is as a result of utilising the weighted average of the two years. Utilising only the rules of the current year, we see that inequality tracks but is always lower than the actual data. This is consistent with the fact that we have not modelled misspecification in modelling taxes and contributions.

We now consider the impact of misspecification in the modelling of taxes and contributions. We do this by replacing the simulated value for taxes and contributions with the variable supplied in the data. We note in Figure 8 that prior to 2009, that replacing simulated taxes and contributions (based upon a weighted average of two years) with the actual value had quite a varied effect, reducing the gap by between $10 \%$ and $50 \%$. This effect is much more consistent however at 30 $40 \%$ when one looks at the change in the gap between actual and simulated based upon the current tax-benefit year. We note however that gap is reduced by a greater degree by improvements in the benefit assumptions.

Modelling benefit non-take-up at the family level, we see that the inequality trend over time remains the same, with curve shifting about a quarter to a half of the gap closed. As noted above, part of the reason for the over-simulation of benefits, is that it is not possible to identify in the EU-SILC data, receipt of benefits of less than a year. Imputing the number of months received on the basis of the difference between actual and simulated benefits, we see that much of the remaining gap is closed in Figure 7. In 2009, this over-compensates pushing inequality over $100 \%$. However this is as a result of utilising the weighted average of the two years. Utilising only the rules of the current year, we see that inequality tracks but is always lower than the actual data. This is consistent with the fact that we have not modelled misspecification in modelling taxes and contributions.

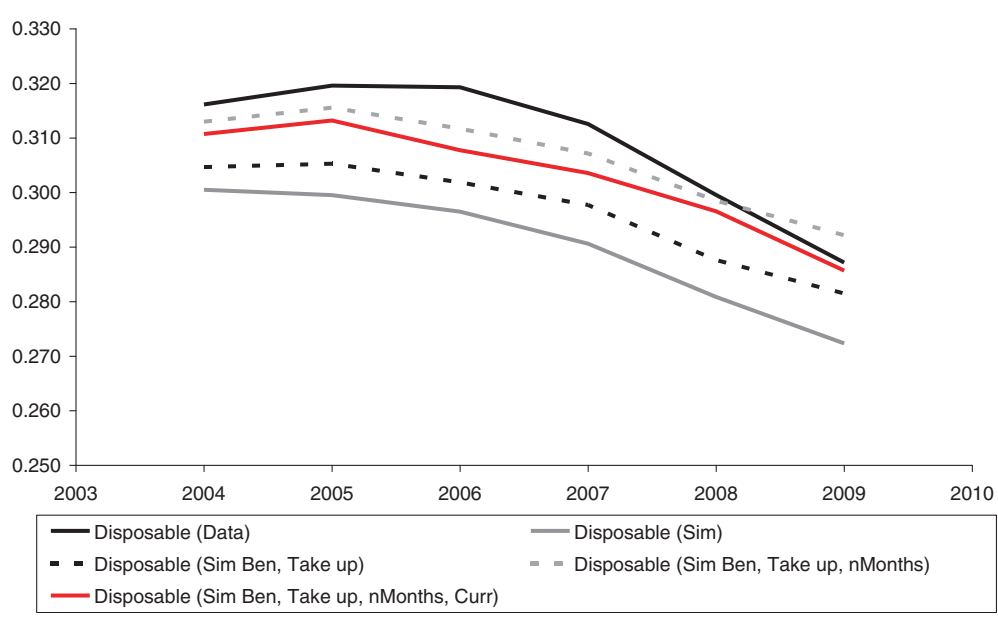

Figure 7 Distribution of disposable income, simulated and actual with different benefit assumptions. Note: Equivalence scale used is the modified OECD scale. 


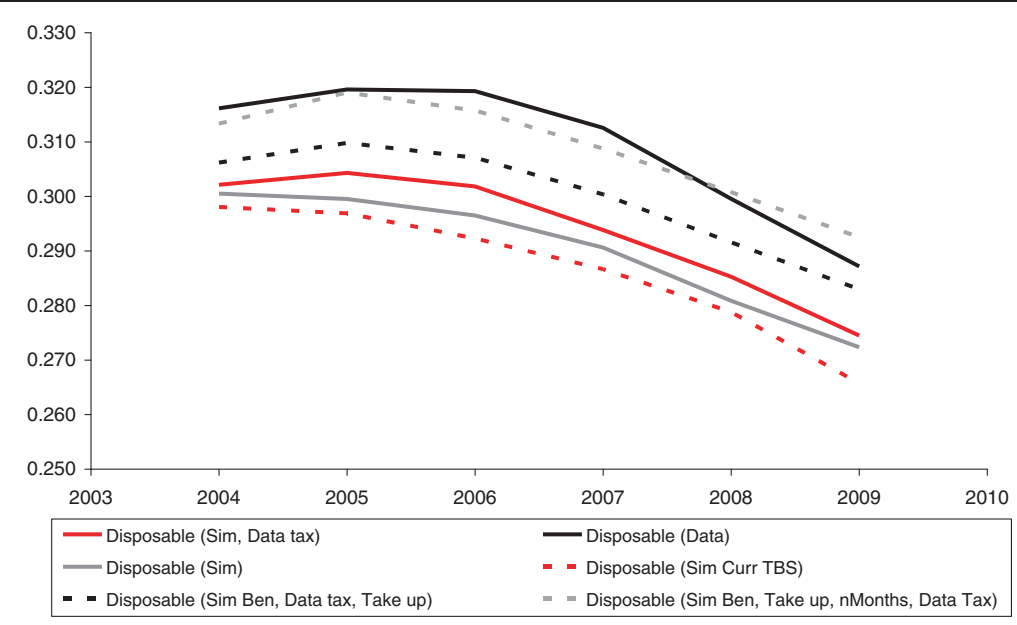

Figure 8 Distribution of disposable income, simulated and actual with different tax assumptions. Note: Equivalence scale used is the modified OECD scale.

We now consider the impact of misspecification in the modelling of taxes and contributions. We do this by replacing the simulated value for taxes and contributions with the variable supplied in the data. We note in Figure 8 that prior to 2009, that replacing simulated taxes and contributions (based upon a weighted average of two years) with the actual value had quite a varied effect, reducing the gap by between $10 \%$ and $50 \%$. This effect is much more consistent however at 30 $40 \%$ when one looks at the change in the gap between actual and simulated based upon the current tax-benefit year. We note however that gap is reduced by a greater degree by improvements in the benefit assumptions.

\section{Market impact}

We now try to understand the trend in different components. We firstly focus on the distribution of market income as measured by the Gini coefficient in Figure 9. We note in particular that the trend in the distribution of market income (excluding zero's) was increasing to 2006, before falling slightly relatively flat in the period before the crisis. After 2007 market inequality widened firstly quite steadily to the 2009, as the wage rate of some sectors such as industry rose, while

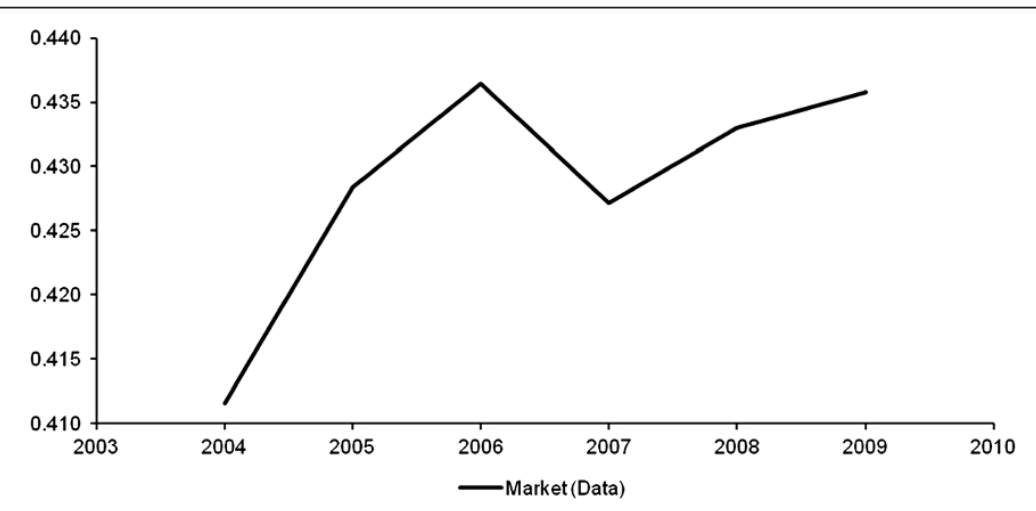

Figure 9 Distribution of market income. Note: Equivalence scale used is the modified OECD scale. 
declining sectors experienced oftentimes falls in nominal wages. This is consistent with the story in Figure 3 above.

\section{Redistributive impact}

We turn now to the impact on changes to the distribution of income that results from changes to policy. We measure redistribution relatively simply, comparing the change
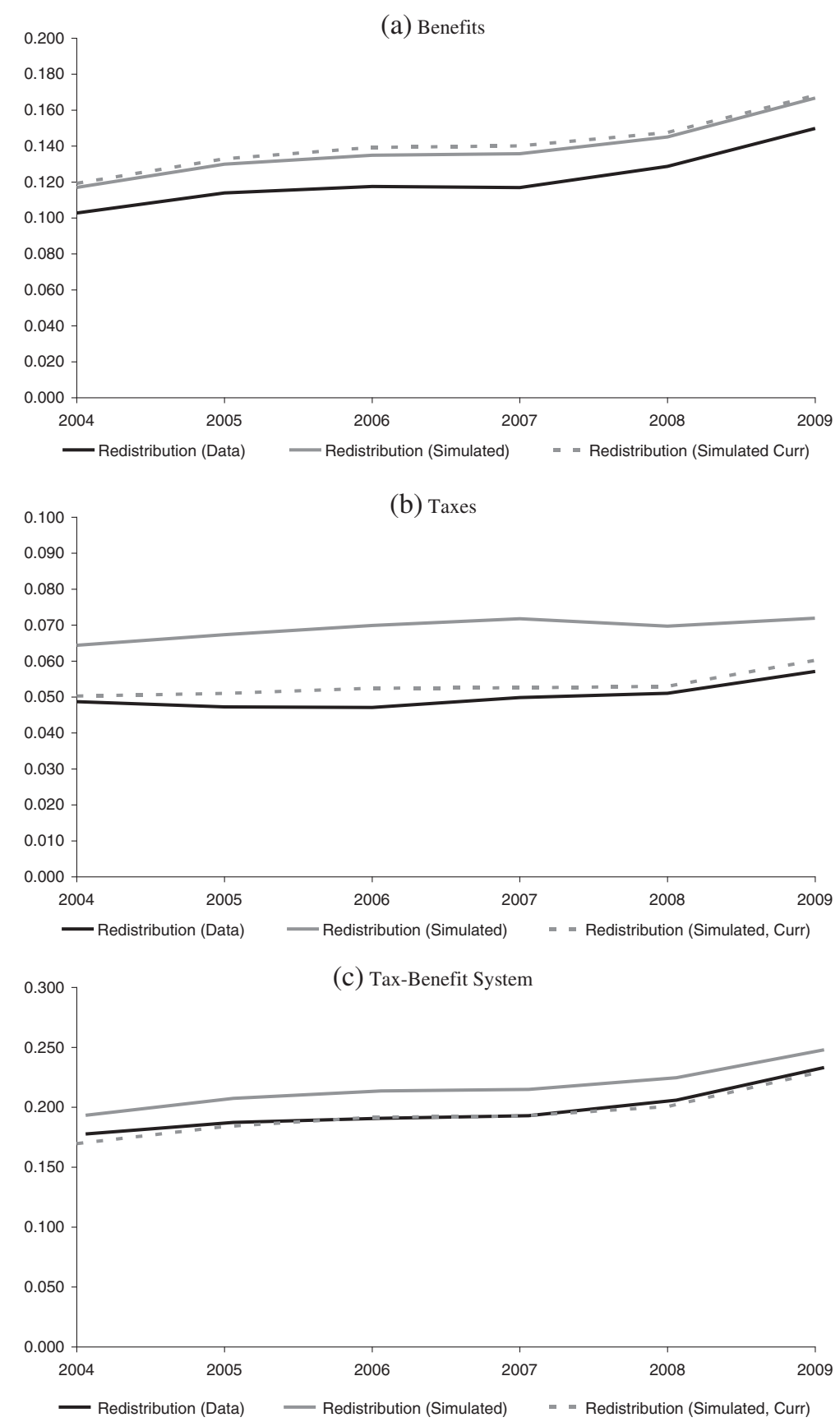

Figure 10 Redistributive impact. Note: Equivalence scale used is the modified OECD scale. Simulated Curr reflects the Simulated Value using the Current Year System (a, b and $\mathbf{c})$. 
in the Gini coefficient between market, gross and disposable incomes. We note that this ignores re-ranking and put off a more detailed examination as to the drivers of redistribution to further work.

Considering first the impact of benefits, we see in Figure 10a, the steady rise in the redistributive impact of the benefit system in the period to 2007, driven by the relative growth in benefits relative to CPI and wage growth during the period. After the onset of the crisis, the redistributive impact of the benefit system ratcheted up, due to increased demand. We will consider in further work, the impact of changes to the level of targeting in the instruments, due to for example changes in the means testing of benefits. As is clear from analyses of the distribution of disposable income above, assuming full take-up and receipt for 12 months increases the redistributive effect of the benefit system relative to the data. We note that there is a relatively difference between the simulated values based upon a weighted average of two years and those based upon the current system.

The redistributive impact of the tax-system revealed in Figure 10b reveals a similar story of rising redistribution, very steadily at first and then rising rapidly post 2008 as some of the tax reforms took hold. We notice a relatively large difference between the weighted average and the current system. This is due to the changing progressivity of the systems. In general the redistributive effect of the current system matches that of the data quite well.

Increasing redistribution can be driven by increased progressivity or greater expenditure. Table 7 decomposes the redistributive effect into progressivity and rate effects. To do this we utilise the Kakwani index of progressivity, that measures the difference between the Lorenz curve and the concentration curve for the relevant instrument. The rate refers to the instrument as a share of pre-instrument income. Both are expressed as an index relative to 2004 to highlight the overall trend. In both the case of taxes and benefits, the progressivity effect has risen over time reflecting the fact that changes to the systems have been relatively targeted. The effect has been stronger on the benefits side due in part to the movement from insurance to assistance benefits as the average duration out of work increased over the crisis. Over the entire period, the rate effect dominates the progressivity effect, so that the redistributive impact has been driven to a larger extent by demand on the part of benefits. In the case of taxation, the rate effect actually fell in the middle part of the period of analysis before rising again with tax and contribution changes in 2009.

\section{Conclusions}

In this paper we attempted to chart the impact of the early part of Ireland's economic crisis from 2008-2009 on the distribution of income. In order to decompose the impact of components of income, we utilised a microsimulation methodology. However the EU-

Table 7 Progressivity and rate effects of policy change

\begin{tabular}{|c|c|c|c|c|}
\hline & \multicolumn{2}{|c|}{ Taxes and levies } & \multicolumn{2}{|c|}{ Benefits } \\
\hline & Progressivity & Rate & Progressivity & Rate \\
\hline 2004 & 100 & 100 & 100 & 100 \\
\hline 2005 & 103 & 98 & 106 & 107 \\
\hline 2006 & 109 & 97 & 107 & 115 \\
\hline 2007 & 107 & 97 & 108 & 120 \\
\hline 2008 & 109 & 98 & 106 & 139 \\
\hline 2009 & 105 & 113 & 112 & 168 \\
\hline
\end{tabular}


SILC User Database, the main potential data source is difficult to use for microsimulation purposes due to benefit aggregation, missing information in relation to the length of benefit receipt and a lack of documentation as to the choices made when producing the data. For relatively uncomplicated tax-benefit systems in Southern and Eastern Europe, Figari et al. (2007) adapted the EU-SILC for use in the EUROMOD tax-benefit framework. However Ireland poses greater challenges. The Irish case is (as is likely the case in many northern European countries) more complicated. This is due to the fact that there are more instruments with more complicated rules and with overlapping values between instruments.

As the microsimulation model can simulate the taxes and contributions contained in the EU-SILC, the main objective required to make the EU-SILC suitable for microsimulation was to disaggregated the incidence of benefits from 6 variables in the EU-SILC to 17 disaggregated variables. To do this we estimated a series of equations from an earlier dataset based upon the European Community Household Panel dataset, together with official statistics in relation to the number of recipients to simulate the incidence of the different types of benefits. We also adjusted the number of months of receipt on the basis of differences between the data and simulated values. Our method also highlighted a number of data quality issues in relation to the inclusion of some payments such as redundancy lump sums within social transfer variables. This methodology is potentially applicable to other countries too and thus could be utilised to develop the EU-SILC for microsimulation purposes.

We undertook a detailed validation of the methodology, finding that the methodology was reasonably effective, subject to the usual consequences of assumptions using microsimulation such as $100 \%$ benefit take-up and under-estimating the impact of non-modelable allowances, full year of receipt for benefits and tax avoidance/evasion in tax system. Overall we found that the simulated and data based approaches generated a similar trend, albeit with lower levels of inequality for these reasons. Modelling benefit take-up, and partial year receipt, we were able to bridge much of the gap between the two approaches, giving us confidence in our methodology.

We utilised the framework to model changes to the level of income inequality from the period just before the crisis in 2004 to after the crisis in 2009. In terms of the impact of the economic crisis, we found that the income inequality fell in the early part of the crisis. Much of this change was due to rising inequality of market incomes, (even when discounting unemployment). This was due to the differential effect of the downturn on different sectors where some sectors such as the construction and public sectors were significantly hit, while the international traded sectors have been relatively immune from the downturn and have seen continued growth. The impact of the tax-benefit system has been to mitigate this upward pressure, with a gradual rise in the redistributive effect of the tax-benefit system driven by an increase in demand primarily on the benefits side and increased progressivity.

\section{Endnotes}

${ }^{1}$ See EUROSTAT, GDP per capita in Purchasing Power Standards (PPS) 1997-2008.

${ }^{2}$ For a broad description of the structure of the Irish tax-benefit system, see O’Donoghue (2004). 
${ }^{3}$ There were much more significant cuts for young people.

${ }^{4}$ According to the CSO, in 2010 changes had been made to the processing of the data which resulted in an incorrect treatment in some cases of tax, income and pension contributions. This became clear when unusual trends in certain categories between 2010 and 2011 were further analysed.

\section{Appendix 1}

Structure of tax-benefit reforms (Table 8).

Table 8 Structure of reforms 2008-2013

\begin{tabular}{|c|c|}
\hline Year & Main structural changes \\
\hline \multirow[t]{2}{*}{2008} & Increase in social welfare payments above CPI \\
\hline & Increases in limits for mortgage interest \\
\hline \multirow[t]{6}{*}{2009} & Introduction of a Pension Levy for Public Servants \\
\hline & Social Welfare rates increased (ahead of CPI) \\
\hline & Halving of Child Care Supplement \\
\hline & Introduction of an income levy \\
\hline & Increase in the standard rate bands \\
\hline & Minor Adjustments to mortgage interest relief \\
\hline \multirow[t]{5}{*}{2009 Suppl. } & Reduction in Social Welfare rates for the young unemployed \\
\hline & Reduction in the duration of mortgage interest to 7 years \\
\hline & Doubling rates of income levy and adjust bands \\
\hline & Doubling rates of health levy and adjust bands \\
\hline & Raise PRSI ceiling \\
\hline \multirow[t]{4}{*}{2010} & Cessation of the Child Care Supplement \\
\hline & Reduction in Child Benefits \\
\hline & Reduction of Public Servant Pay \\
\hline & Reduction in working age social welfare benefits \\
\hline \multirow[t]{8}{*}{2011} & Second homes tax Reduction in Child Benefits \\
\hline & Reduction in working age social welfare benefits \\
\hline & Reduction in pay of new entrants to the public service \\
\hline & Reduction in public service pensions \\
\hline & $\begin{array}{l}\text { Replacement of income and health levy with the Universal Social Charge, } \\
\text { which has a broader base }\end{array}$ \\
\hline & Reduction of bands and credits by $10 \%$ \\
\hline & Removal of ceiling for PRSI for contributions \\
\hline & Restriction of relief for PRSI for pension contributions \\
\hline 2011 Jobs initiative & Reduced Employer's PRSI \\
\hline \multirow[t]{5}{*}{2012} & Change to Mortgage Interest Relief deduction rate \\
\hline & Change to the exemption level for the Universal Social Charge \\
\hline & Introduction of a Household Charge (Flat rate property tax) \\
\hline & Changes to rates of child benefit \\
\hline & Ending of lone parent half payment for period of entry to labour market \\
\hline \multirow[t]{3}{*}{2013} & Reduction in Child Benefits \\
\hline & Household Property Tax \\
\hline & Some Changes to Benefits \\
\hline
\end{tabular}




\section{Appendix 2}

Mapping of benefit variables (Table 9).

Table 9 Mapping of benefit variables

\begin{tabular}{|c|c|c|c|}
\hline Social protection benefit & $\begin{array}{l}\text { No. of Recipients } \\
(2010)-1000 \text { 's }\end{array}$ & Modelled benefit & EU-SILC benefit \\
\hline State pension (Contributory) & 280.4 & \multirow{2}{*}{$\begin{array}{l}\text { State pension (Contributory \& } \\
\text { transitory) }\end{array}$} & \multirow[t]{3}{*}{ Old age benefits } \\
\hline State pension (Transitory) & 10.2 & & \\
\hline State pension (Non-contributory) & 97.2 & State pension (Non-contributory) & \\
\hline $\begin{array}{l}\text { Widow(er)'s contributory } \\
\text { pension }\end{array}$ & 114.6 & Widow(er)'s contributory pension & \multirow[t]{2}{*}{ Survivor's benefits } \\
\hline $\begin{array}{l}\text { Widow(er)'s non-contributory } \\
\text { pension }\end{array}$ & 2.0 & $\begin{array}{l}\text { Widow(er)'s non-contributory } \\
\text { pension }\end{array}$ & \\
\hline Deserted wife's benefit & 8.4 & \multirow[t]{2}{*}{ Deserted wife's benefit/allowance } & \multirow[t]{7}{*}{ Family benefits } \\
\hline Deserted wife's allowance & 0.5 & & \\
\hline One parent family allowance & 92.3 & One parent family allowance & \\
\hline Maternity benefit & 23.5 & Maternity benefit & \\
\hline Child benefit & 591.4 & Child benefit & \\
\hline Other child related benefits & 1.5 & $\mathrm{n} / \mathrm{a}$ & \\
\hline Family income supplement & 28.2 & Family income supplement & \\
\hline Illness benefit & 81.3 & Illness benefit & Sickness benefits \\
\hline Invalidity pension & 50.8 & \multirow[t]{4}{*}{ Invalidity pension } & \multirow[t]{8}{*}{ Disability benefits } \\
\hline Blind pension & 1.5 & & \\
\hline Injury benefit & 0.8 & & \\
\hline Disablement pension & 13.7 & & \\
\hline Disability allowance & 101.1 & Disability allowance & \\
\hline Carer's benefit & 1.6 & \multirow[t]{2}{*}{ Carer's benefit/allowance } & \\
\hline Carer's allowance & 50.6 & & \\
\hline Other illness benefits & 0.9 & $\mathrm{n} / \mathrm{a}$ & \\
\hline Jobseeker's benefit & 123.5 & Jobseeker's benefit & \multirow{7}{*}{$\begin{array}{l}\text { Unemployment } \\
\text { benefits }\end{array}$} \\
\hline Jobseekers's allowance & 261.9 & \multirow[t]{3}{*}{ Jobseeker's allowance } & \\
\hline Farm assist & 10.7 & & \\
\hline $\begin{array}{l}\text { Supplementary welfare } \\
\text { allowance }\end{array}$ & 37.4 & & \\
\hline Pre-retirement allowance & 6.0 & Pre-retirement allowance & \\
\hline Back to work allowances & 9.0 & \multirow{2}{*}{$\begin{array}{l}\text { Back to work/education } \\
\text { Allowances }\end{array}$} & \\
\hline Back to education allowance & 21.1 & & \\
\hline
\end{tabular}

Source: Department of Social Protection Social Welfare Statistics 2010. 


\section{Appendix 3}

Logit models of benefit take-up (Table 10).

Table 10 Logit models of benefit take-up

\begin{tabular}{|c|c|c|c|c|c|c|}
\hline & 2004 & 2005 & 2006 & 2007 & 2008 & 2009 \\
\hline Age & $0.015^{*}$ & 0.002 & 0.0082 & $0.0162^{* *}$ & $0.0148^{* *}$ & $0.0167^{* *}$ \\
\hline Non benefit household income & $-0.3785^{* * *}$ & $-0.3632^{* * *}$ & $-0.4472^{* * *}$ & $-0.4395^{* * *}$ & $-0.324^{* * *}$ & $-0.2037^{* *}$ \\
\hline $\begin{array}{l}\text { Simulated receipt of unemployment } \\
\text { benefits }\end{array}$ & 0.1179 & $-0.626^{* *}$ & $-0.8447^{* * *}$ & $-0.6446^{* *}$ & $0.5667^{* *}$ & 0.1518 \\
\hline Simulated receipt of survivor benefits & $-1.4418^{* * *}$ & $-2.3788^{* * *}$ & $-1.9545^{* * *}$ & $-2.0104^{* * *}$ & -0.3928 & $-0.7043^{*}$ \\
\hline $\begin{array}{l}\text { Simulated receipt of } \\
\text { disability benefits }\end{array}$ & 0.2387 & -0.324 & $-1.0189^{* * *}$ & $-1.0238^{* * *}$ & 0.2256 & -0.0124 \\
\hline Total simulated benefit receipt & 0 & 0.00004 & $0.0001^{* * *}$ & $0.00009^{* * *}$ & $0.0001^{* * *}$ & 0.00002 \\
\hline In employment & $0.5753^{* *}$ & $0.6855^{* * *}$ & $0.8319^{* * *}$ & $0.4305^{*}$ & $0.4588^{* *}$ & $0.4428^{*}$ \\
\hline Is a farmer & -0.5086 & -0.6533 & -0.4308 & -0.3645 & $-0.8272^{* *}$ & $-1.2007^{* * *}$ \\
\hline Retired & $0.8546^{* * *}$ & 0.4189 & 0.1007 & 0.1221 & $0.5052^{*}$ & $0.6225^{* *}$ \\
\hline Married & 0.1346 & $0.6812^{* * *}$ & $1.1447^{* * *}$ & $0.5571^{*}$ & $0.4651^{*}$ & 0.1549 \\
\hline Widowed & -0.2407 & $0.6187^{*}$ & -0.3704 & $-0.6617^{*}$ & -0.0464 & -0.0883 \\
\hline Separated or divorced & $-1.0764^{* * *}$ & -0.4815 & $-0.9053^{* * *}$ & $-1.0323^{* * *}$ & $-1.069^{* * *}$ & $-0.7219^{* *}$ \\
\hline Number of children aged 0-11 & -0.398 & $-0.466^{* *}$ & -0.106 & -0.2375 & 0.5033 & -0.0403 \\
\hline Number of children aged 12-15 & 0.2507 & -0.2266 & 0.0605 & 0.0653 & $-0.3472^{*}$ & -0.2155 \\
\hline Suburban & 0.0772 & -0.2786 & $-0.4095^{*}$ & -0.3254 & -0.1127 & 0.1652 \\
\hline Rural & $-0.347^{*}$ & $-0.3389^{*}$ & $-0.3571^{*}$ & -0.3427 & $-0.3345^{*}$ & -0.0658 \\
\hline University educated & $-0.561^{* *}$ & $-0.4588^{*}$ & $-0.5654^{* *}$ & 0.1587 & $-0.5162^{* *}$ & 0.0084 \\
\hline Upper secondary educated & $-0.5145^{* *}$ & $-0.3738^{*}$ & $-0.5526^{* * *}$ & $-0.5288^{* * *}$ & 0.1078 & -0.0244 \\
\hline Constant & $2.5637^{* * *}$ & $3.3866^{* * *}$ & $3.18^{* * *}$ & $2.8931^{* * *}$ & $1.6974^{* * *}$ & $1.8536^{* * *}$ \\
\hline N & 3446 & 3938 & 3773 & 3768 & 3834 & 3746 \\
\hline Pseudo R2 & 0.0967 & 0.1201 & 0.1542 & 0.1625 & 0.0789 & 0.0585 \\
\hline
\end{tabular}

Source: Sologon and O'Donoghue (2013).

* significant at $10 \%$.

** significant at $5 \%$.

*** significant at $1 \%$.

\section{Annex 4: Benefit validation statistics}

At the aggregate level, our model performs relatively well for an analysis of simulated total benefits. Given the aggregation of the benefits in the SILC and the room for measurement and reporting error in the data collection in terms of the classification of benefits received, we have grouped benefits into categories for comparison. We find that overall we over estimate total benefit expenditure in our model in 2004 relative to the official statistics for 2004 by about $8 \%$. This is consistent with an assumption of full-take up of benefits. We under-report unemployment receipts which is consistent with the results in Table 10 that the uncalibrated SILC data has a lower unemployment rate than that of external control totals (Table 11).

Table 11 Comparing simulated benefits with official statistics (2004 - $€ \mathrm{~m}$ )

\begin{tabular}{llll}
\hline & Official statistics (2004) & Simulated & Ratio \\
\hline Old age \& survivors & 3663 & 4195 & 114.5 \\
Unemployment & 1832 & 1505 & 82.1 \\
Family & 2516 & 2781 & 110.5 \\
Sickness and disability & 1812 & 2128 & 117.4 \\
Total & 9823 & 10609 & 108.0 \\
\hline
\end{tabular}




\section{Competing interests}

The IZA Journal of European Labor Studies is committed to the IZA Guiding Principles of Research Integrity.

The authors declare that they have observed these principles.

\section{Acknowledgements}

The authors are grateful for helpful comments provided at the IZA-OECD conference in Paris and from an anonymous referee.

Responsible editor: Alan Barrett

\section{Author details}

${ }^{1}$ Teagasc Rural Economy and Development Programme, Teagasc Mellows Campus, Athenry, Ireland. ${ }^{2}$ University of Liverpool, Liverpool, UK.

Received: 30 May 2013 Revised: 24 September 2013 Accepted: 26 November 2013

Published: 23 Dec 2013

\section{References}

Callan T, Keane C (2009) Non-cash benefits and the distribution of economic welfare. Econ Soc Rev 40(1):49-71, Economic and Social Studies

Callan T, Nolan B (2010) Inequality and the crisis: the distributional impact of tax increases and welfare and public sector pay cuts. Econ Soc Rev 41(4):461-471

Callan T, O'Donoghue C, O'Neill C (1994) Analysis of basic income schemes for Ireland. ESRI Policy Research Series Paper No, Dublin, p 21

Callan T, Keeney MJ, Nolan B, Walsh JR (2001) Reforming tax and welfare ESRI policy research series 42. Economic and Social Research Institute, Dublin

Callan T, Keane C, Walsh JR, Lane M (2010a) From Data to Policy Analysis: Tax-Benefit Modelling using SILC 2008. J Stat Soc Inq Soc Ireland, Vol. XL

Callan T, Nolan B, Keane C, Walsh JR (2010b) Inequality and the Crisis: The Distributional Impact of Tax Increases and Welfare and Public Sector Pay Cuts. The Economic and Social Review, Economic and Social Studies 41(4):461-471

Callan T, Nolan B, Walsh J (2011) The economic crisis, public sector pay and the income distribution (Vol. 32, pp. 207225). Emerald Group Publishing Limited

Callan T, Keane C, Savage M, Walsh JR (2012) Distributional impact of tax, welfare and public sector pay policies: 2009-2012. Quarterly Economic Commentary 2012, 45-56. ESRI, Dublin

Decoster A, Loughrey J, O'Donoghue C, Verwerft D (2010) How regressive are indirect taxes? A microsimulation analysis for five European countries. J Policy Anal Manage 29(2):326-350

Figari F, Horacio L, Holly S (2007) Using the EU-SILC for policy simulation: prospects, some limitations and suggestions. EUROMOD Working Paper No EM1/07

Levy H, Mercader-Prats M (2003) EUROMOD Country Report SPAIN. https://www.iser.essex.ac.uk/files/msu/emod/ documentation/countries/spain/crsp0701.pdf

Loughrey J, O'Donoghue C (2012) The welfare impact of price changes on household welfare and inequality 1999-2011. Econ Soc Rev 43(1):31-66

Machado J, Mata J (2005) Counterfactual decomposition of changes in wage distributions using quantile regression. J Appl Econ 20:445-465

O'Donoghue C (2004) Redistributive forces in the Irish tax-benefit system. Journal of the Statistical and Social Inquiry Society of Ireland. Dublin, Vol. XXXII, 2002/2003:33-69.

O'Donoghue C, Loughrey J (2013) Analysis on the existing national and cross national experience on microsimulation of social indicators of income and poverty. Mimeo Report to Eurostat

O'Riain S (2012) The crisis of financialisation in Ireland. Econ Soc Rev 43(4):497-533

Voitchovsky S, Maitre B, Nolan B (2012) Wage inequality in Ireland's "Celtic tiger" boom. Econ Soc Rev 43(1):99-133

Whelan K (2010) Policy lessons from Ireland's latest depression. Econ Soc Rev 41(2):225-254

$10.1186 / 2193-9012-2-23$

Cite this article as: O'Donoghue et al:: Using the EU-SILC to model the impact of the economic crisis on inequality. IZA Journal of European Labor Studies 2013, 2:23

\section{Submit your manuscript to a SpringerOpen ${ }^{\circ}$ journal and benefit from:}

- Convenient online submission

- Rigorous peer review

- Immediate publication on acceptance

- Open access: articles freely available online

- High visibility within the field

Retaining the copyright to your article

Submit your next manuscript at $\boldsymbol{\wedge}$ springeropen.com 